\title{
Development of Intelligent Wind Turbine Generator with Tandem Wind Rotors and Double Rotational Armatures* (1st Report, Superior Operation of Tandem Wind Rotors)
}

\author{
Toshiaki KANEMOTO** and Ahmed Mohamed GALAL***
}

\begin{abstract}
This paper proposes the superior wind turbine generator, which is composed of the tandem wind rotors and the double rotational armature type generator without the conventional stator. The large-sized front wind rotor and the small-sized rear wind rotor drive respectively the inner and the outer armatures of the generator, in keeping the rotational torque counterbalanced. Such operating conditions enable to make the output higher than the conventional wind turbine and to keep the output constant in the rated operating mode without using the brake and/or the pitch control mechanisms. Such wonderful advantages in the generating mode are discussed and verified experimentally with the model turbine generator.
\end{abstract}

Key Words: Wind Mill, Blade, Tandem Rotor, Generator, Armature, Generating Mode, Characteristic, Cut-in Wind Speed, Rated Wind Speed

\section{Introduction}

The wind power has been positively/effectively utilized to cope with the warming global environment, and the propeller type wind turbines have played a main role in the electric power generation ${ }^{(1)}$. The conventional wind turbines with large-sized wind rotor generate high output in the moderately strong wind. The output of the smallsized wind rotor is low but such a wind rotor is suitable for weak wind. That is, the size of the wind rotor must be correctly/appropriately selected in conformity with the wind circumstances. Besides, the wind turbines are equipped with the brake and/or the pitch control mechanisms in general, to suppress the abnormal rotation and the overload generated at the stronger wind, and to keep a good quality of the electric power.

The authors invented the superior wind turbine generator, as shown in Fig. 1. This unit is composed of the large-sized front wind rotor, the small-sized rear wind rotor and the peculiar generator with the inner and the outer rotational armatures. The front and the rear wind rotors

* Received 26th September, 2005 (No. 05-4167)

** Faculty of Engineering, Kyushu Institute of Technology, 1-1 Sensui, Tobata, Kitakyushu, Fukuoka 804-8550, Japan. E-mail: turbo@tobata.isc.kyutech.ac.jp

*** Graduate School of Engineering, Kyushu Institute of Technology, 1-1 Sensui, Tobata, Kitakyushu, Fukuoka 804-8550, Japan.

E-mail: e584103m@tobata.isc.kyutech.ac.jp drive the inner and the outer armatures, respectively. This unit was named "Intelligent Wind Turbine Generator" by the authors, as the rotational speeds of the tandem wind rotors are adjusted pretty well in cooperation with the two armatures of the generator in response to the wind speed, namely the power load. This unit is applicable to the area with not only rich wind circumstances such as Middlegrunden offshore wind farm ${ }^{(2)}$, but also poor circumstances having weak and fluctuated wind as at Japanese

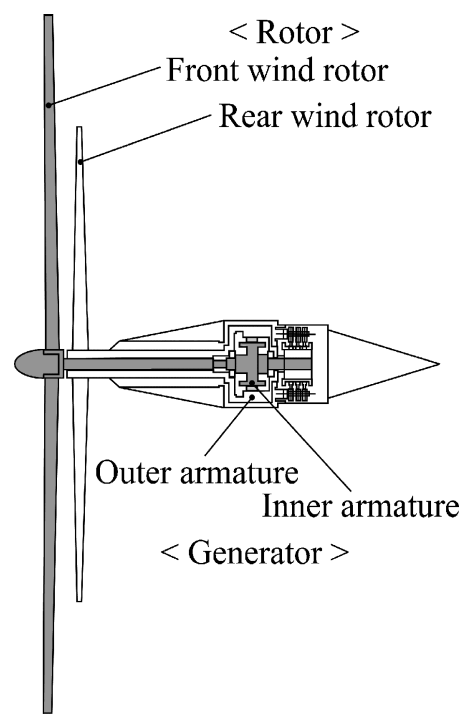

Fig. 1 Schematic drawing of the Intelligent Wind Turbine Generator 
areas.

In this paper, the superior operation of the tandem wind rotors is interpreted accompanying with the presentation of the wonderful advantages, and is verified with the model turbine generator. Besides, the effects of the blade profiles on the turbine performances are investigated preliminarily to optimize the rotor profiles.

\section{Superior Operation of Tandem Wind Rotors}

The fundamental concept of the tandem wind rotors has been proposed before ${ }^{(3)}$. Kowintec Co., Ltd. has succeeded only to increase the output of the wind turbine using the tandem wind rotors and had the prototype wind turbines $^{(4)}$. Professor Ushiyama could also increase the output using the tandem wind rotors ${ }^{(5)}$. On the contrary, the operation of the tandem wind rotors proposed by the authors quite differs from these wind rotors, and is in cooperation with the double rotational armature type generator without the conventional stator. In such a generator, the rotational torque is counter-balanced between the inner and the outer armatures in the generator ${ }^{(6)}$. Then, as for the wind rotors, the rotational torque of the front wind rotor must be the same, in the opposite direction, as that of the rear wind rotor, but the rotational directions of both rotors/armatures are free. The rotational direction and speed of the rotor/armature are automatically adjusted in response to the wind circumstance (see Fig. 2).

Both wind rotors start to rotate at the low wind speed, namely the cut-in wind speed, but the rear wind rotor counter-rotates against the front wind rotor. The increase of the wind speed makes both rotational speeds increase, and the rotational speed of the rear wind rotor becomes faster than that of the front wind rotor because of its small size. The rear wind rotor reaches the maximum rotational speed at the rated wind speed. With more increment of the wind speed, the rear wind rotor decelerates gradually and begins to rotate at the same direction of the front wind rotor so as to coincide with the larger rotational torque of the front wind rotor. Such behavior of the rear wind ro-

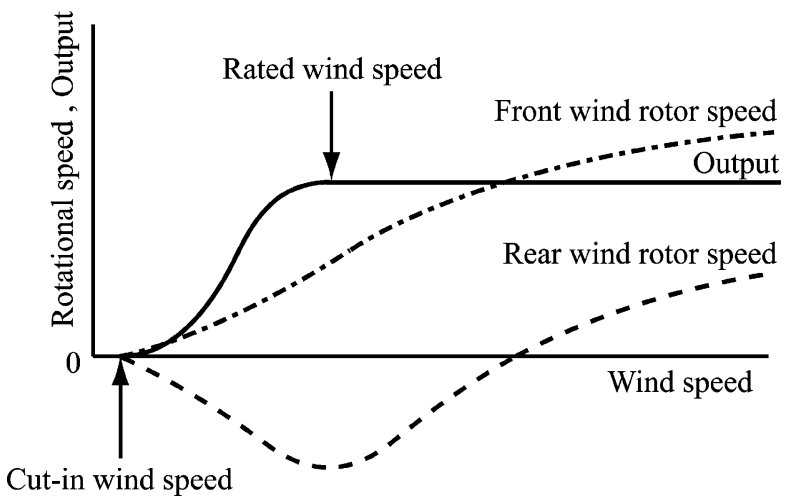

Fig. 2 Predictable operation of the proposed Intelligent Wind Turbine Generator tor is induced from the reason why the small-sized wind rotor must work as the blowing mode against the attacking wind because the wind rotor in the turbine mode can not generate adequately the rotational torque corresponding to the large-sized front wind rotor. The behavior of the front and the rear rotors also depend on the blade profiles and the flow conditions between both rotors, and will be discussed quantitatively in the following reports.

As a result, the above operating conditions enable successfully to guarantee the quality of the electric power, namely power supply frequency, in the rated operation without the conventional brake and/or the pitch control mechanisms. That is, the relative rotational speed between the front and the rear wind rotors affects directly the quality of the electric power. The power supply frequency can be kept constant when the wind rotors are designed so as to keep the relative rotational speed constant. The output can also be kept constant when the wind rotors are designed so as to keep the value, which is the relative rotational speed multiplied by the rotational torque, constant. Moreover, the counter-rotation under the rated wind speed makes the output higher in the poor wind circumstances, that is a remarkable advantage for the area which has no acceptable wind circumstance at the power generation.

The authors already developed the counter-rotating type synchronous generator ${ }^{(6)}$, which may be applied to isolated wind power stations. Continuously, the authors have prepared the double rotational armature type induction generator to drive successfully the proposed tandem wind rotors at the grid-connected electric power system. The relative rotational speed and the output can be adjusted delicately and accurately by the frequency modulation, namely the rotational slip control of the inner armature, through the inverter.

\section{Verification of Superior Operation}

\subsection{Model wind turbine and experiments}

The model, which is composed of the tandem wind rotors and the conventional induction generator whose stator is directly connected to the rear wind rotor shaft and plays the role of the outer rotational armature, was preliminarily prepared and set at the outlet of the wind tunnel (the nozzle diameter is $600 \mathrm{~mm}$ ). It was confirmed that the rotational direction of the rear wind rotor changes in response to the wind speed as predicted above, while the front wind rotor rotates in the same direction.

It is difficult, however, not only to know the rotational torque but also to get the fruitful materials for optimizing the blade profile, using the above model. Then, the shafts of the wind rotors were connected directly and respectively to the isolated motor with the inverter in place of the peculiar generator, as shown in Fig. 3. In this apparatus, the rotational torque of the rear wind rotor must be forced to coincide with the rotational torque of the front 


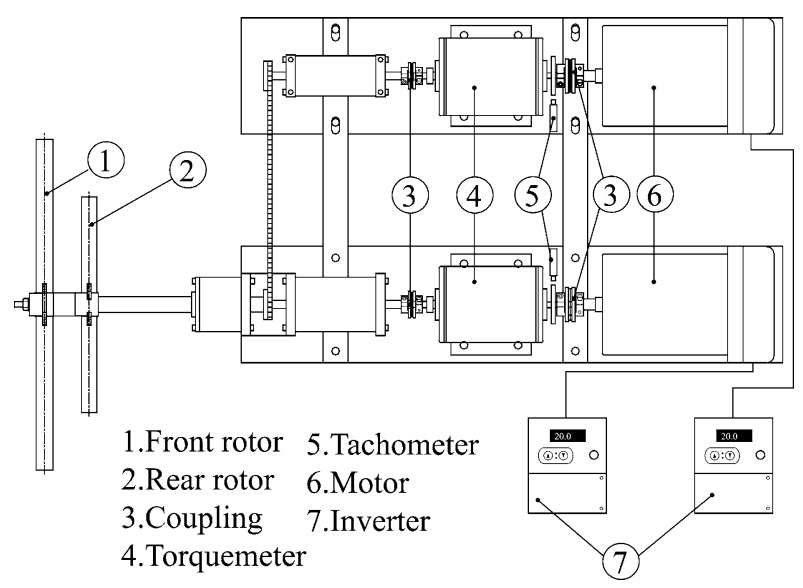

Fig. 3 The experimental apparatus

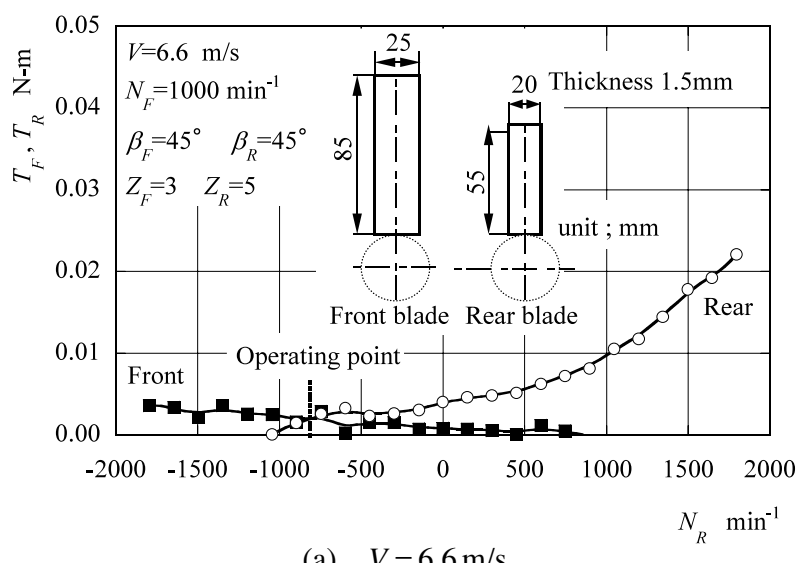

(a) $\quad V=6.6 \mathrm{~m} / \mathrm{s}$

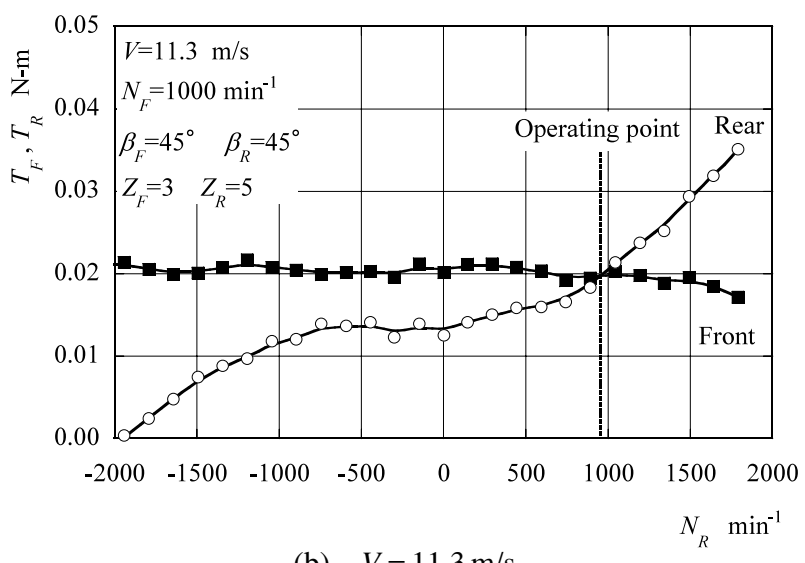

(b) $\quad V=11.3 \mathrm{~m} / \mathrm{s}$

Fig. 4 Torque characteristics and operating point

wind rotor, replacing the armature works. Figure 4 shows the rotational torque $T$ (subscripts $F$ and $R$ mean the front and the rear wind rotors) against the rotational speed of the rear wind rotor $N_{R}$, in keeping the rotational speed of the front wind rotor $N_{F}$ and the wind speed $V$ constant $\left(N_{F}=1000 \mathrm{~min}^{-1}, V=6.6 \mathrm{~m} / \mathrm{s}\right.$ and $\left.11.3 \mathrm{~m} / \mathrm{s}\right)$, where the flat blade profiles are given in this figure, $Z_{F}$ and $Z_{R}$ are the front and the rear blade numbers, $\beta_{F}$ and $\beta_{R}$ are the front and the rear blade setting angles (see Fig. 5). The rotational torque $T$ is evaluated, in this paper, without the

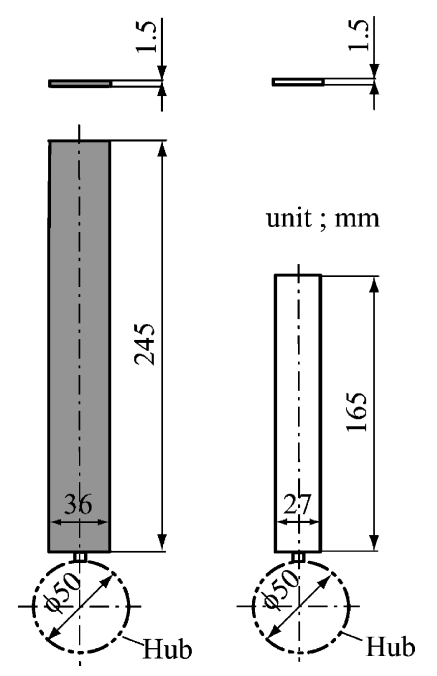

Front rotor blade AF Rear rotor blade AR

(a) Blade profiles

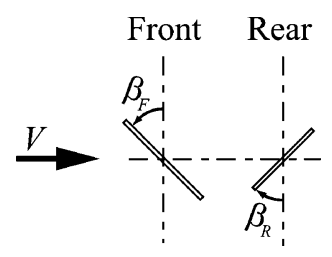

(b) Blade setting angles

Fig. 5 Flat blade A

mechanical torque of the bearings and the pulley system, which are pre-examined using this apparatus without the wind rotors. The torque $T_{R}$ is naturally negative value but was presented with the positive value in this figure, to be compared easily with $T_{F}$. The negative rotational speed of the rear wind rotor $N_{R}$ is in the turbine mode, and the positive speed is in the blowing mode. The torque of the front wind rotor $T_{F}$ is scarcely affected by the rotational speed $N_{R}$, though $T_{F}$ is affected by the wind speed $V$. On the contrary, the torque of the rear wind rotor $T_{R}$ is affected obviously by not only the wind speed but also the rotational speed of the rear wind rotor. The torque $T_{R}$ becomes large with the increase of the wind speed $V$ and the rotational speed $N_{R}$. The tandem rotors run at the operating point where $T_{F}=-T_{R}$, as mentioned above and marked in Fig. 4.

The flat blades, which were named the flat blade A, with the thickness of $1.5 \mathrm{~mm}$ were prepared as shown in Fig. 5, to verify fundamentally the superior operation of the tandem wind rotors. The diameter of the front wind rotor equipped with the blade $\mathrm{AF}$ is $d_{F}=550 \mathrm{~mm}$ and the rear wind rotor equipped with the blade $A R$ is $d_{R}=390 \mathrm{~mm}$, where the diameter of both cylindrical hubs is $50 \mathrm{~mm}$, and front hub does not have the nose cone. The rotational torque of the wind rotor was counter-balanced by the rotational speed controller, namely the inverter, in accordance with the above procedure. The maximum 

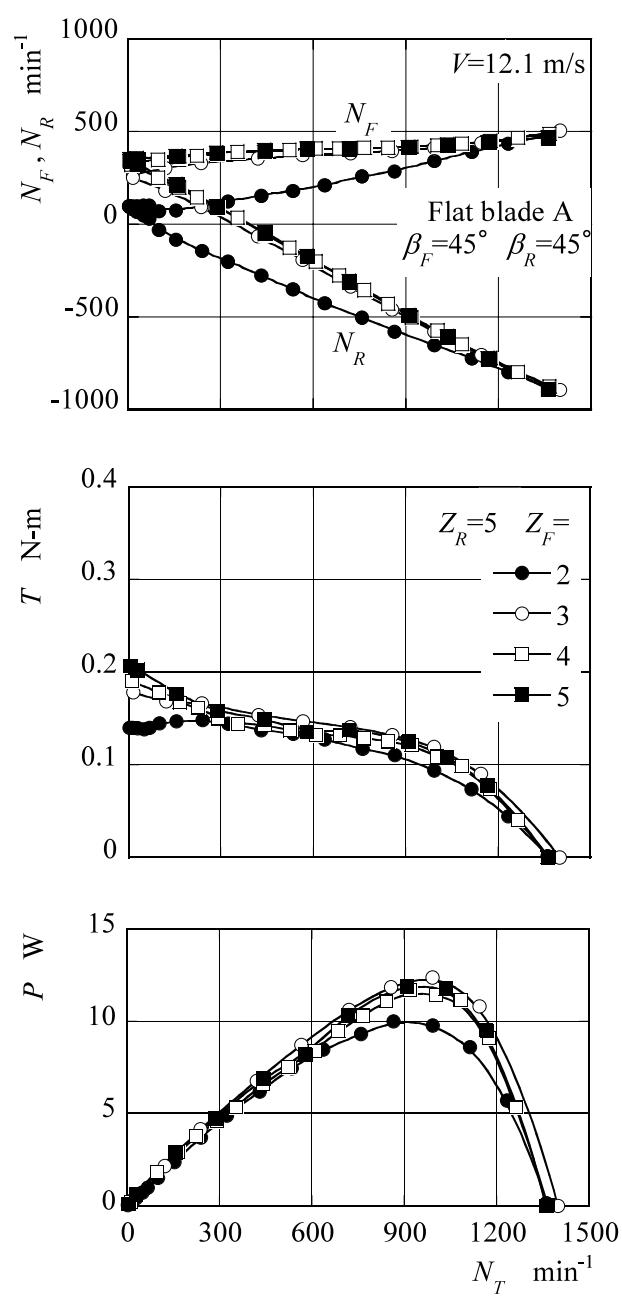

(a) Effect of the front blade number
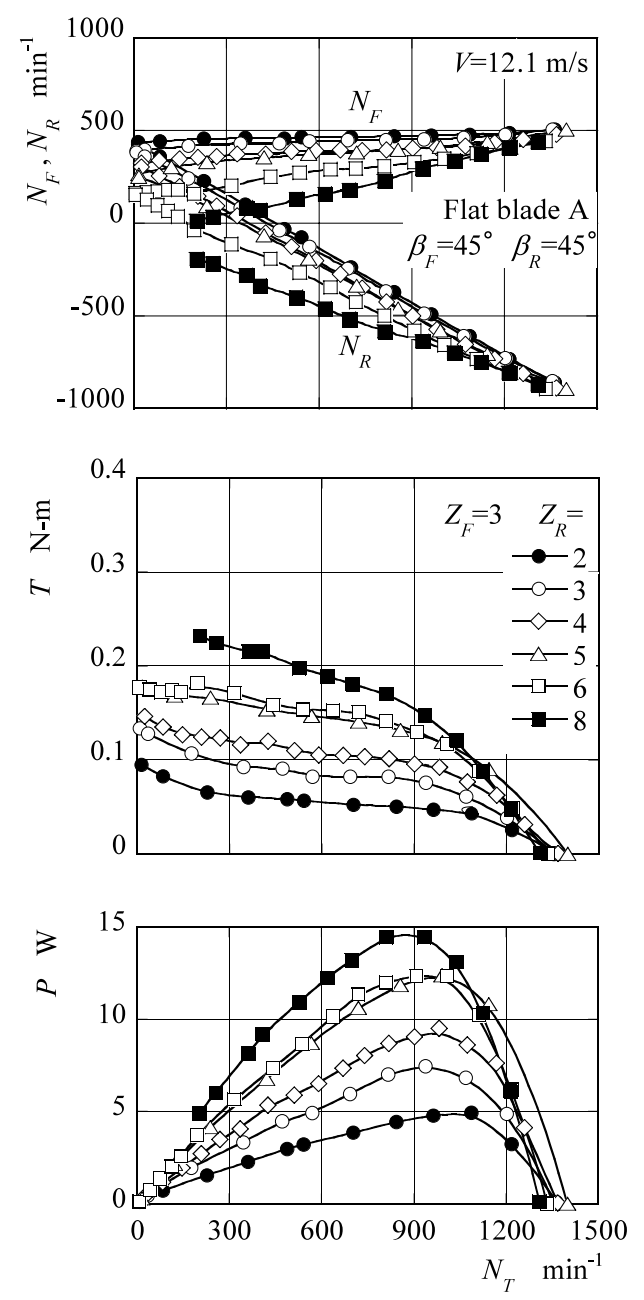

(b) Effect of the rear blade number

Fig. 6 Fundamental characteristics of the tandem rotors

Reynolds number based on the blade chord and relative velocity at the blade tip is $R_{e \max }=5 \times 10^{4}$ in the experiments. Unfortunately, it is impossible to make the Reynolds number as large as the prototype, on account of the wind tunnel capacities. The model tests do not give the absolute values of the prototype, but present beneficial materials for discussions on the wind rotor work as the first step.

\section{2 Fundamental characteristics of wind rotors}

The effects of the blade number on the characteristics of the wind rotors are shown in Fig. 6, where the front and the rear blade setting angles are $\beta_{F}=\beta_{R}=45$ degrees, $N_{T}$ is the relative rotational speed $\left(=N_{F}-N_{R}\right.$, the rotational direction of the front wind rotor is positive), $T$ is the rotational torque $\left(=T_{F}=-T_{R}\right)$, and $P$ is the output. It is important to pay attention to the behavior of the rear wind rotor. That is, the rear wind rotor must run not only in the opposite direction (counter-rotation) against the front wind rotor when the relative rotational speed $N_{T}$ is faster or the rotational torque is smaller, but also in the same direction when the relative rotational speed is slower or the rotational torque is larger. As shown in Fig. 6(a), the rotational torque $T$ and the output $P$ are scarcely affected by the number of the front blades $Z_{F}$, but the front wind rotor with two blades $\left(Z_{F}=2\right)$ is not acceptable because of the absence of the counter-rotation. This figure suggests that the optimum blade number of the front wind rotor is $Z_{F}=3$ judging from the rotational direction and the output.

On the contrary, the rear blade number $Z_{R}$ has great influence on the characteristics [Fig.6(b)]. The rotational speed of the front wind rotor $N_{F}$ becomes obviously slower and the speed of the rear rotor $N_{R}$ becomes faster, as the absolute value, with the increase of the blade number of the rear wind rotor. The rear wind rotor with many blades is not acceptable because, at this condition, the rear wind rotor does not rotate at the same direction of the front wind rotor, but it increases the rotational torque and the output. Taking account of the above rotating conditions and the output, the optimum blade number of the rear wind rotor is $Z_{R}=4-6$.

These results, however, may not be applied to the prototype as they are, because these are special cases obtained 
from the flat blades accompanying with the flow separation/stall on large scale.

Figure 7 shows the output and the rotational torque coefficients of the wind rotors with the optimum blade numbers $Z_{F}=3$ and $Z_{R}=5$, where $\lambda_{T}$ is the relative tip speed ratio [(relative tip speed between the front and the rear wind rotors)/(wind speed)], $C_{P}$ is the output coefficient $\left[=P /\left(\rho A V^{3} / 2\right), A\right.$ : area of the front wind rotor $]$ and $C_{M}$ is the rotational torque coefficient $\left[=T /\left(\rho A V^{2} d_{F} / 4\right)\right]$. The experimental coefficients at the various wind speeds are represented with one curve against $\lambda_{T}$, that is, the similarity laws were confirmed to the wind speed, for not only the single wind rotor but also the tandem wind rotors. The best relative tip speed ratio giving the maximum output is about three times as fast as that of the single/front wind rotor given by the fine dotted line. That is induced mainly from the rear wind rotor speed $N_{R}$. Then, the maximum output is about three times as high as that of the single wind rotor, in this experiment using the flat blades.

The optimum tip speed ratio $7-8$ of the conventional propeller type wind turbine ${ }^{(7)}$ can not be obtained naturally in the single wind rotor, because the flat blades work at the abnormal attack angle such as the negative angle in
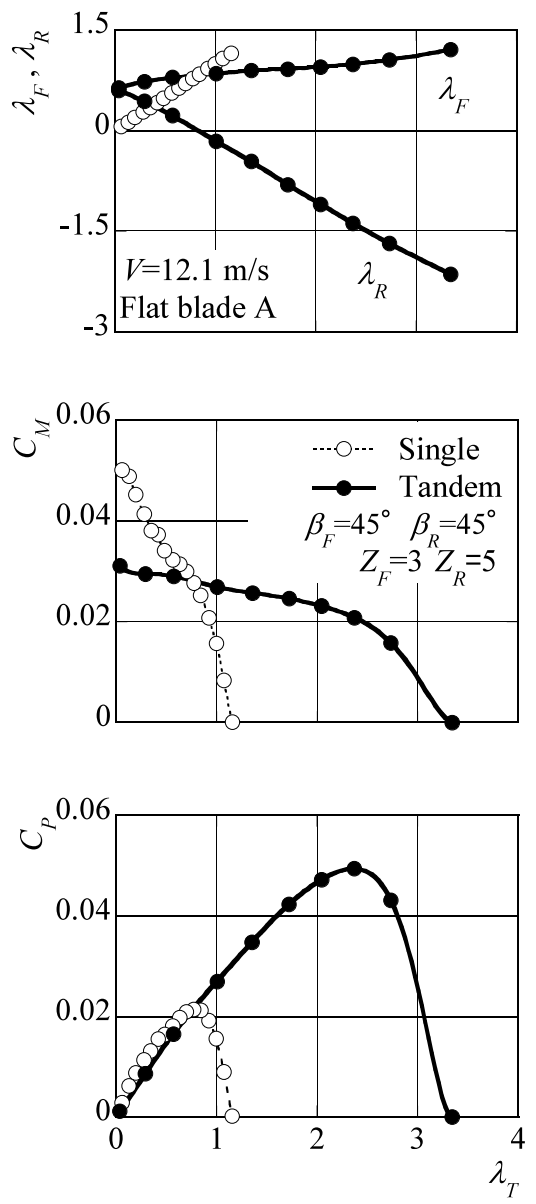

Fig. 7 Output and rotational torque coefficients in comparison with the single wind rotor the blade tip side and the positive angle in the blade root side.

\subsection{Rotor work meeting expectations}

Figure 8 shows the performances of the tandem wind rotors with the optimum blade numbers in the generating mode, where the rated wind speed was tentatively set at $=14.5 \mathrm{~m} / \mathrm{s}$. The tandem wind rotors were driven at the maximum output point, namely the best relative tip speed ratio, in the slower wind speed, namely under the rated wind speed, and driven so as to keep the output constant in the rated operation as given with the full line in Fig. 9,

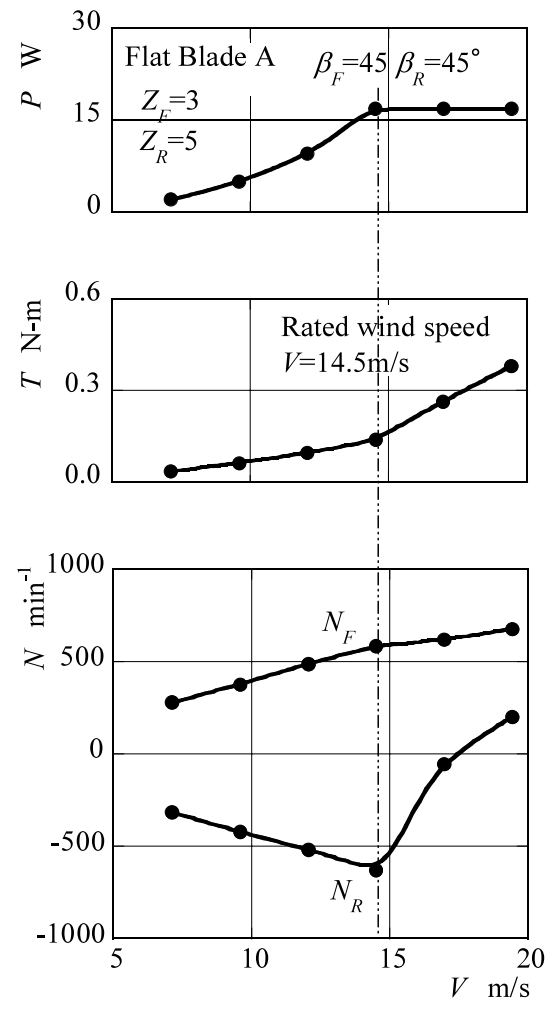

Fig. 8 Performances at the generating mode

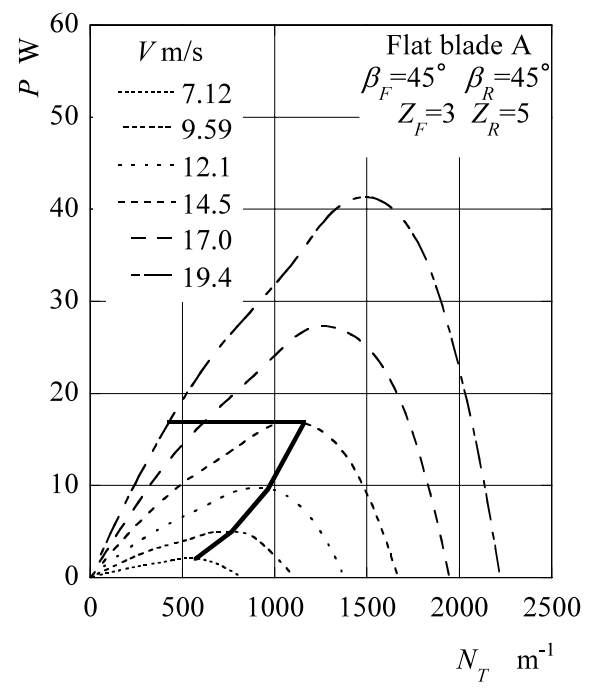

Fig. 9 Operating point 
where the dashed lines are experimental output of the tandem wind rotors. The rotational speeds $N_{F}$ and $N_{R}$ take the superior behaviors in response to the wind speed, as predicted in chapter 2 . The abnormally high rotation of the front wind rotor $N_{F}$, which can not be avoided by the conventional single wind rotor without the breaking and/or pitch control mechanism, is also suppressed well by the rotation of the rear wind rotor $N_{R}$ in the blowing mode at the faster wind speed.

\section{Effects of Blade Profiles on Performances}

This chapter investigates preliminarily the effects of the blade profiles on the characteristics of the tandem wind rotor to get the optimum profiles in the near future, as the superior operations of the tandem wind rotors were verified above. The parameter remodeled in this chapter is individually presented but the other parameters are the same as presented before.

\subsection{Effects of blade setting angle}

The maximum output coefficient $C_{P \max }$ and the tip speed ratios giving $C_{P \max }\left(\lambda_{T B E P}, \lambda_{F B E P}, \lambda_{R B E P}\right.$ : the relative, the front and the rear tip speed ratios) of the flat blade A are shown in Fig. 10, when the front blade angle $\beta_{F}$ is changed in keeping the rear blade angle $\beta_{R}=45$ degrees or $\beta_{R}$ is changed in keeping $\beta_{F}=45$ degrees. The optimum angle of the front blade is nearly close to $\beta_{F}=13$ degrees at $\beta_{R}=45$ degrees and the angle of the rear blade is nearly close to $\beta_{R}=22$ degrees at $\beta_{F}=45$ degrees. Then, the relative tip speed ratio $\lambda_{T B E P}$ is faster due to $\lambda_{F B E P}$ as for the optimum setting angle of the front blade [Fig. 10 (a)], and $\lambda_{T B E P}$ is faster due to $\lambda_{R B E P}$ as for the optimum setting angle of the rear blade [Fig. 10(b)]. Such results mean that the attack angles must be optimized as the tandem wind rotors, taking account of the flow interactions between both wind rotors.

\subsection{Effects of flow separation on blade surface}

The flow separates from the flat blade surface due to the abnormal attack angle, and the flow separation affects markedly the wind rotor work. To investigate such effects, the flat blades B shown in Fig. 11 were prepared. The chord of the front and the rear blades were changed linearly in the blade height, and the surface areas are almost the same as those of the flat blade A given in Fig. 5. Figure 12 shows the output and the rotational torque coefficients, $C_{P}$ and $C_{M}$, in comparison with those of the flat
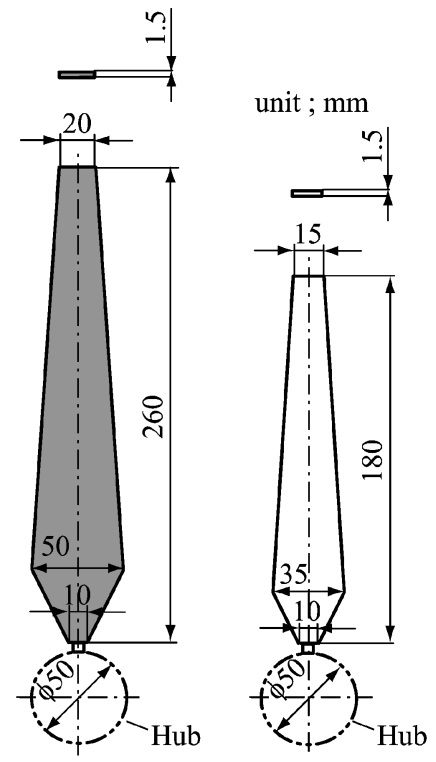

Front rotor blade BF Rear rotor blade BR

Fig. 11 Flat blade B
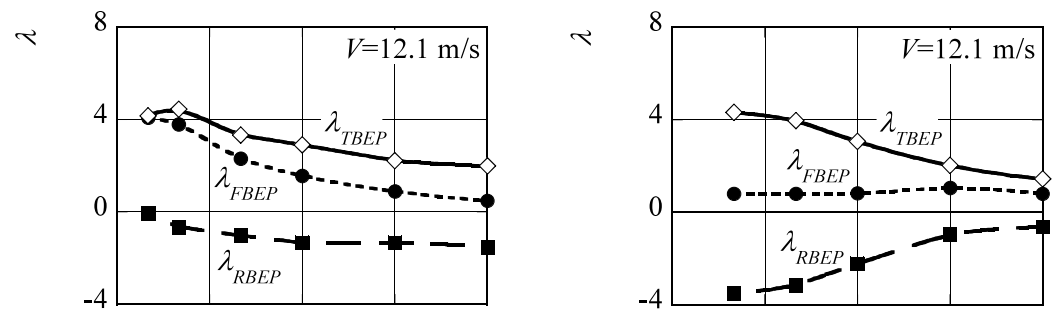

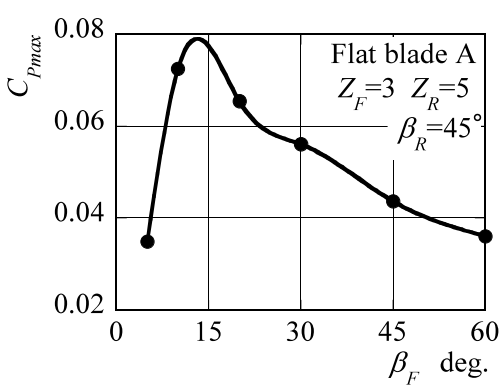

(a) Effect of the front blade angle

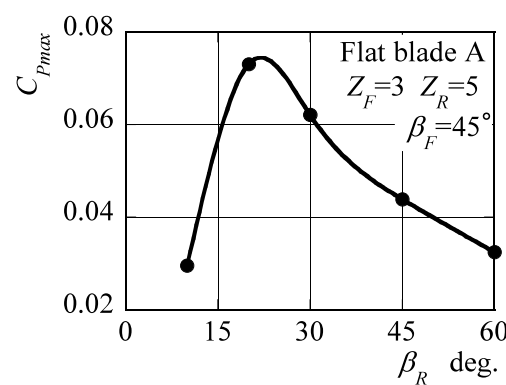

(b) Effect of the rear blade angle

Fig. 10 Effect of the blade setting angle on the maximum output 

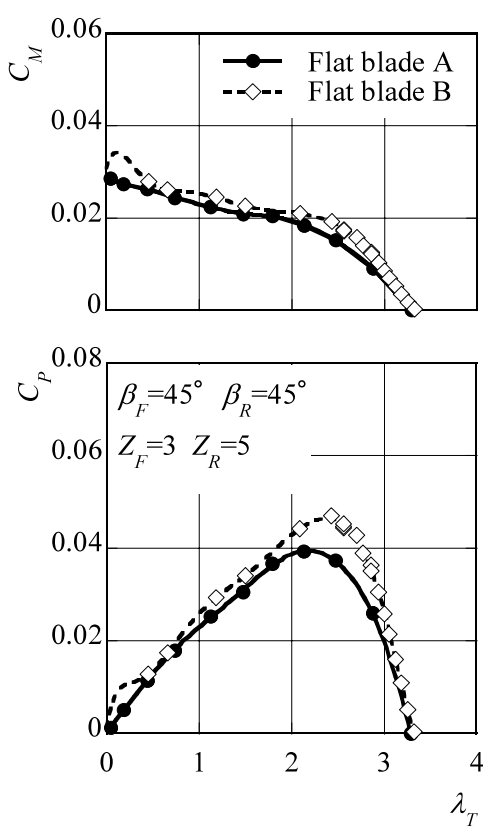

Fig. 12 Effect of chord on the characteristics

blade A. Both coefficients of the flat blade B are higher than those of the blade $\mathrm{A}$ and the relative tip speed ratio $\lambda_{T}$ giving the maximum $C_{P}$ becomes slightly faster. The attack angle of the flat blade is changed markedly from the positive at the blade root to the negative at the blade tip. The negative attack angle close to the blade tip causes the flow stall on the pressure surface of the blade, and such a stall deteriorates the rotational speed and torque. The drag force induced from the stall becomes large with the increase of the attack angle and/or the blade chord. That is, the rotor work of the flat blade B with the short chord at the tip is slightly better as compared with the blade A with the long chord, as the rotational torque is determined mainly by the flow condition in the tip side.

\subsection{Effect of blade camber and thickness}

The work of the rotor can be improved, more and more, by optimizing the blade profile such as the attack angle (twist), the camber, the thickness and so on. As the first step, improvement of the work of the rotor was tried with the two-dimensional cambered blade $\mathrm{C}$ shown in Fig. 13. Figure 14 shows the coefficients $C_{P}$ and $C_{M}$ of the cambered blade $C$. It is noticed significantly that the work of the cambered blades is obviously better and the relative tip speed ratio giving the maximum $C_{P}$ becomes faster.

\section{Concluding Remarks}

The superior wind turbine generator, which is composed of the tandem wind rotors and the double rotational armature type generator without the conventional stator, was proposed. The large-sized front wind rotor and the small-sized rear wind rotor drive respectively the inner and the outer armatures, in keeping the rotational torque
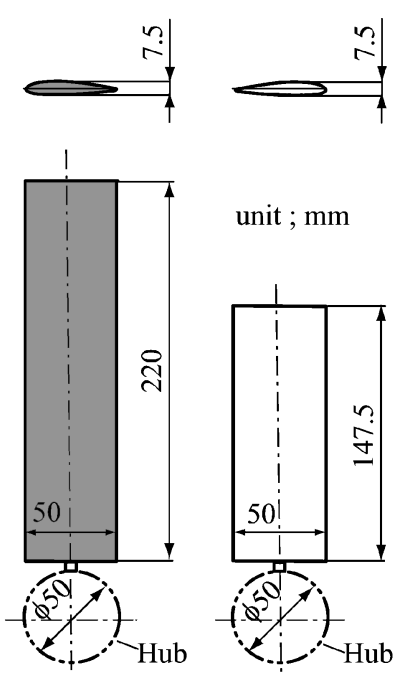

unit ; mm

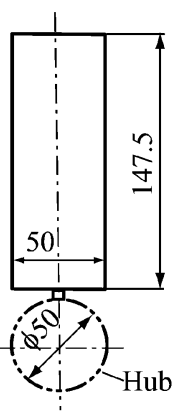

Front rotor blade CF Rear rotor blade CR

Fig. 13 Cambered blade C
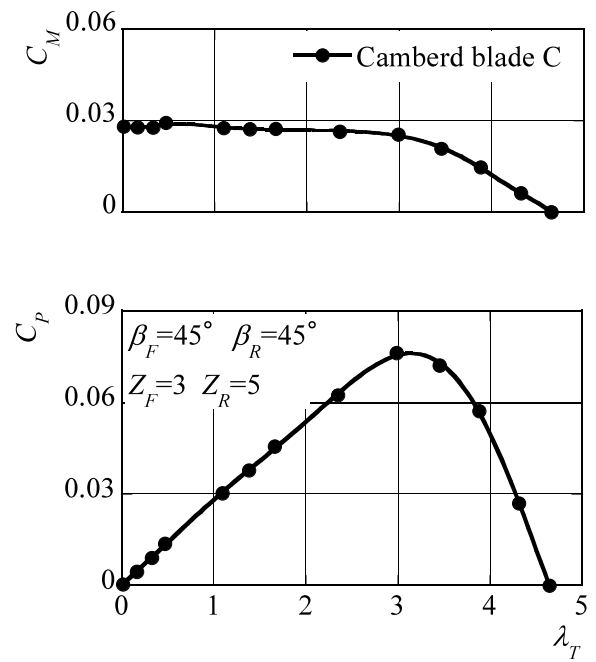

Fig. 14 Effect of the camber and the thickness on the characteristics

counter-balanced. It was verified experimentally that such operating conditions enable to make the output higher than the conventional turbine and to keep the output constant in the rated operation mode without the brake and/or the pitch control mechanism.

To put this Intelligent Wind Turbine Generator to practical use, the authors started to get the advanced technology of prototypes.

\section{Acknowledgements}

The authors wish to thank Mr. Masaki Tonda, Mr. Yosuke Tsuda, Mr. Yuki Fukuoka, Mr. Yuji Inada, Miss Yuko Konno and Mr. Kota Ikeda, who graduated form Faculty of Engineering in Kyushu Institute of Technology, for helping with the experiments. This research was supported in part by Research Foundation of Kyushu Industrial Technology Center in Japan and Grant-in-aid for 
Scientific Research C(2) (2005) of Japan Society for the Promotion of Science.

\section{References}

( 1 ) Liliana, S. and Ion, P., Wind Turbines: An Environmental Technology, Proceedings of the 9th International Symposium on Transport Phenomena and Dynamics of Rotating Machinery, Honolulu, (2002), CDROM FD-ABS-061.

( 2 ) Soerensen, H.C., Larsen, J.H., Olsen, F.A., Svenson, J. and Hansen, S.R., Middlegrunden 40 MW Offshore Wind Farm: A Prestudy for the Danish Offshore 750 MW Wind Program, Proceedings of the 10th International Offshore and Polar Engineering Conference, Vol.1 (2000), pp.484-491.

( 3 ) Sper, D.A., Wind Turbine Technology, (1994), p.93,
ASME Press.

(4) http://www.kowintec.com/English/intro/info.htm

( 5 ) Ushiyama, I., Shimota, T. and Miura, Y., An Experimental Study of the Two Staged Wind Turbines, Proceedings of World Renewable Energy Conference, (1996), pp.909-912.

( 6 ) Kanemoto, T., Tanaka, D., Kashiwabara, T., Uno, M. and Nemoto, M., Tidal Current Power Generation System Suitable for Boarding on a Floating Buoy, International Journal of Offshore and Polar Engineering, Vol.11, No.1 (2001), pp.77-79.

( 7 ) Fingersh, L. and Carlin, P., Results from the NREL Variable-Speed Test Bed: Collection of the 1998 ASME Wind Energy Symposium Technical Papers Presented at the 36th AIAA Aerospace Sciences Meeting and Exhibit, Trans. ASME, (1998), pp.233-237. 